\title{
Fuzzy Logic Based Frequency Control of Multi-Area Electrical Power System Considering Non-Linearities and Boiler Dynamics
}

\author{
${ }^{1}$ Yogendra Arya, ${ }^{2}$ Narendra Kumar, ${ }^{3}$ S.K. Gupta and ${ }^{3}$ Pankaj Chawla \\ ${ }^{1}$ Department of Electrical and Electronics Engineering, \\ Maharaja Surajmal Institute of Technology, Janakpuri, New Delhi, India \\ ${ }^{2}$ Department of Electrical Engineering, Delhi Technological University, Delhi, India \\ ${ }^{3}$ Department of Electrical Engineering, \\ Deenbandhu Chhotu Ram University of Science and Technology, Murthal, Sonepat, India
}

\begin{abstract}
This study presents the Load Frequency Control (LFC) of four-area interconnected reheat thermal power system using Fuzzy Logic based PI controller (FLPI). The system is incorporated with governor dead band, generation rate constraint non-linearities and boiler dynamics. The conventional PI controller does not yield adequate control performance when considering the non-linearities and boiler dynamics. The aim of FLPI controller is to restore the frequency and tie line power very smoothly to its nominal value in the shortest possible time. Four performance criteria, i.e., settling time, peak overshoot, Integral Absolute Error (IAE) and Integral of Time Multiplied Absolute Error (ITAE) are utilized for the comparison. The comparison between the conventional PI controller and the proposed controller show that the proposed controller can generate the best dynamic response following load perturbation in either area of the system. Robustness of the proposed controller is achieved by analyzing the system responses with varying system parameters.
\end{abstract}

Key words: Area control error, boiler dynamics, four-area power system, fuzzy logic controller, generation rate constraint, governor deadband, load frequency control, proportional plus integral controller

\section{INTRODUCTION}

The main objectives of an interconnected electrical power system control are generating, transmitting and distributing electric power as economically and reliably as possible while maintaining the quality of power, voltage magnitude and frequency within the acceptable limits. Large-scale power systems comprise interconnected subsystems (control areas) forming coherent groups of generators whereas connection between the areas is made using tie-lines. Each control area has its own generation and is responsible for its own load and scheduled interchanges with neighboring areas.

The load in a given power system is continuously changing. Consequently, the system frequency and tie-line flows deviate from the nominal values. The load frequency controller is needed to maintain the system frequency and inter-area flows at the desired nominal values. Steam input to turbo generators (or water input to hydro generators) must continuously be regulated to match the active power demand, failing which the machine speed will vary with consequent change in frequency which may be highly undesirable as frequency variations in interconnected power systems can cause large-scale serious instability problems (Elgerd, 1982). Since, frequency of power system is mainly affected by change in active power and voltage magnitude is mainly affected by change in reactive power, these are controlled separately (Fosha and Elgerd, 1970; Gupta, 2009). Two control loops are used to achieve load frequency control. They are primary frequency control loop and secondary frequency loop which is called Load Frequency Control (LFC). The main function of the LFC is to compliment the primary control to eliminate the frequency and net tie-line interchange deviations (Sadat, 2002).

In multi-area power system if a load variation occurs at any one of the areas in the system, the frequency related with this area is affected first and then that of other areas are also affected from this perturbation through tie-lines.

Therefore, a control strategy is needed that not only maintains constancy of frequency and desired tie-power flow but also achieves zero steady state error and inadvertent interchange. In most of the researches, the

Corresponding Author: Yogendra Arya, Department of Electrical and Electronics Engineering, Maharaja Surajmal Institute of Technology, Janakpuri, New Delhi, India 
boiler system effects and the governor dead band effects have been neglected in the load frequency control studies for simplicity. But for the realistic analysis of system performance, it shall be adequate to incorporate these effects (Chidambaram and Velusamy, 2005). Several control strategies such as optimal control (Fosha and Elgerd, 1970), classical control (Malik et al., 1988), suboptimal control, adaptive control (Pan and Liaw, 1989), variable structure control (Kumar et al., 1985), etc., have been employed in the past to explore an optimum controller for LFC.

The conventional control strategy for LFC problem is to take the integral of Area Control Error (ACE) as the control signal. LFC systems basically use simple integral controller and PI controller whose parameters are usually tuned based on classical control or trial and error approaches.

The integral controller provides zero steady-state frequency deviation but it exhibits poor dynamic performance. The basic approaches to design controllers are not effective to obtain good dynamic performance for various load changes scenarios and disturbances in an interconnected power system. Adaptive controllers with self-adjusting gain settings have been proposed to overcome this deficiency. Despite, the promising results achieved by these adaptive controllers, the control adjustments are complicated and require online system model identification. Centralized information structure and knowledge of all system parameters are technically difficult and economically unjustifiable. There are some authors who have applied variable structure control (Kumar et al., 1985) to make the controller insensitive to system parameters change.

Some fuzzy gain scheduling of PI controllers have been proposed to solve these problems. Artificial Neural Networks have been successfully applied to the LFC problem with the promising results (Chaturvedi et al., 1999; Luy et al., 2008; Oysal, 2005). Moreover, Fuzzy Logic Control Techniques (Mathur and Manjunath, 2006; Cam and Kocaarslan, 2005; Ertugrul and Kocaarslan, 2005; Sreenath et al., 2008) for LFC problem are mostly based on fuzzy gain scheduling of integral and proportional Plus Integral (PI) controller parameters. A Hybrid Neuro-fuzzy (HNF) control strategy has been proposed for LFC to improve performance of the fuzzy controller (Panda et al., 2009).

Many researchers have applied Genetic Algorithm (GA) controllers to improve the dynamic performance of the power system (Prasanth and Kumar, 2008). In a control schemes LFC by automatic design of the fuzzy rules in the fuzzy gain scheduling control approach by genetic algorithm is proposed (Jaung and $\mathrm{Lu}, 2005$ ). The concept of fuzzy set theory was introduced by Zadeh and it was first introduced in 1979 for solving power system problems. Fuzzy set theory can be considered as a generalization of the classical set theory. In classical set theory, an element of the universe either belongs to or does not belongs to the set, i.e., $\mathrm{x} \in \mathrm{A}$ or $\mathrm{x} \notin \mathrm{A}$. Thus, the degree of association of an element is crisp.

Mathematically, a fuzzy set is a set with gradual boundaries, i.e., transition from non-membership to membership is gradual rather than abrupt. A membership function assigns to every $\mathrm{x} \in \mathrm{A}$, a value from unit interval $[0,1]$ rather than from the two element set $\{0,1\}$.

The membership function is usually designed by taking into consideration the requirement and constraints of the system under consideration. Fuzzy logic implements human experiences and preferences via membership functions and fuzzy rules. In this study, in order to improve system performance, the rules for the gains are chosen identical for the proposed FLPI controller. The proposed controller is compared with a conventional PI controller. For the PI controller, the gains of proportional and integral are chosen 0.01 and 0.04 , respectively. These values are determined experimentally. The comparison between the proposed FLPI controller and the conventional PI controller shows that the overshoots, settling time, integral absolute error and integral of time multiplied absolute error with proposed FLPI controller are better than the conventional PI controller.

\section{MATERIALS AND METHODS}

Four-area power system: An interconnected power system is considered as being divided into control areas which are connected by tie-lines. In each control area, all generators are assumed to form a coherent group. The power system investigated in this study contains four-area interconnected by six tie-lines as shown in Fig. 1 and 2. For conventional integral controller, the overall system shown in Fig. 2 and 3 can be modeled in a state space form of:

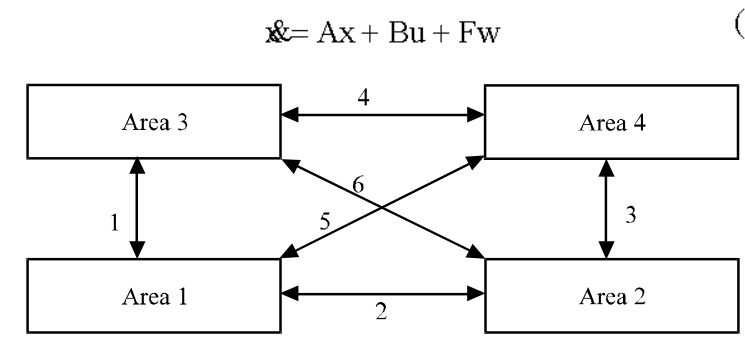

Fig. 1: Schematic diagram of interconnected four-area power system with six tie-lines 
Int. J. Elec. Power Eng., 5 (5): 203-213, 2011

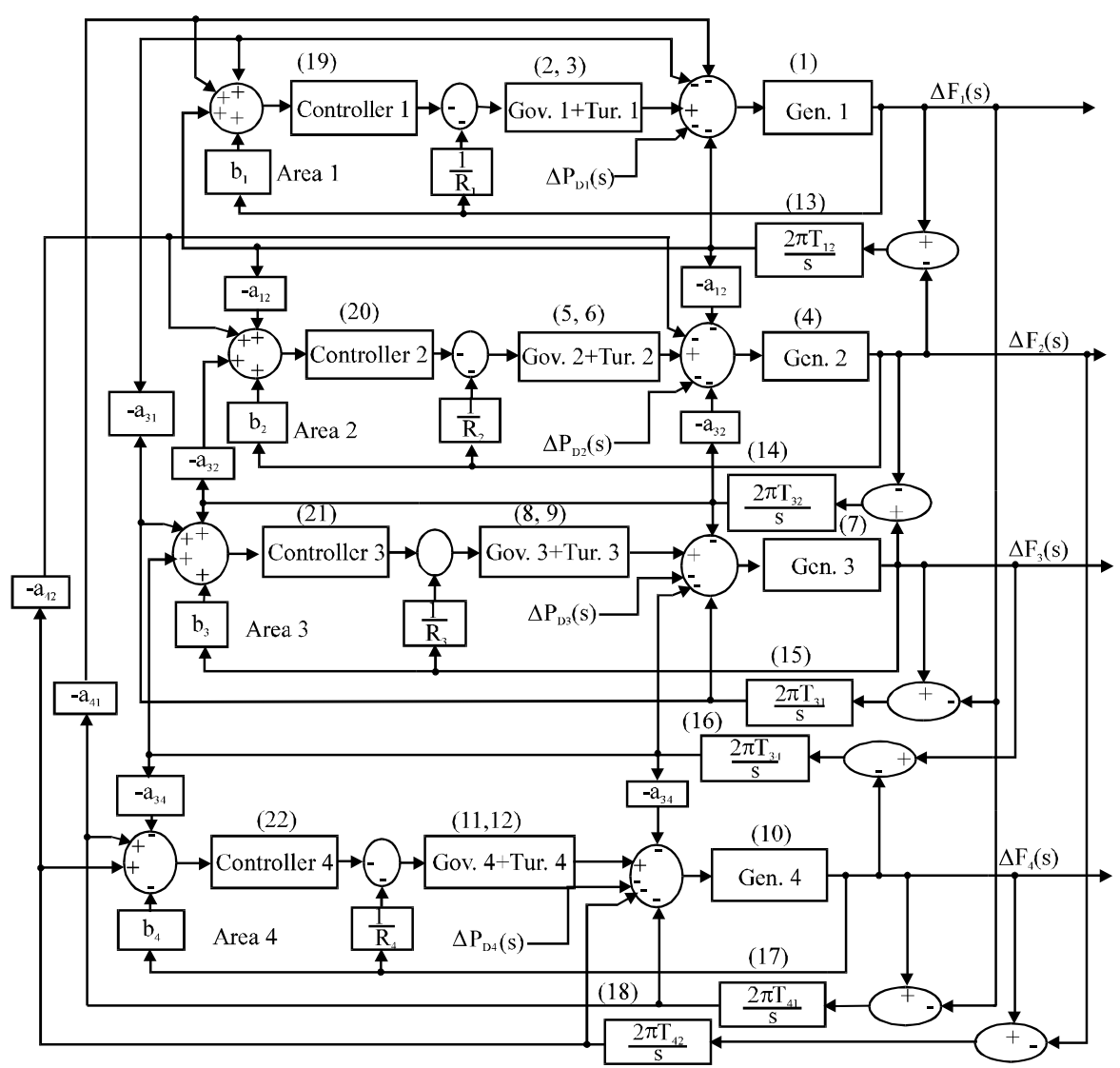

Fig. 2: Block diagram of four-area interconnected power system

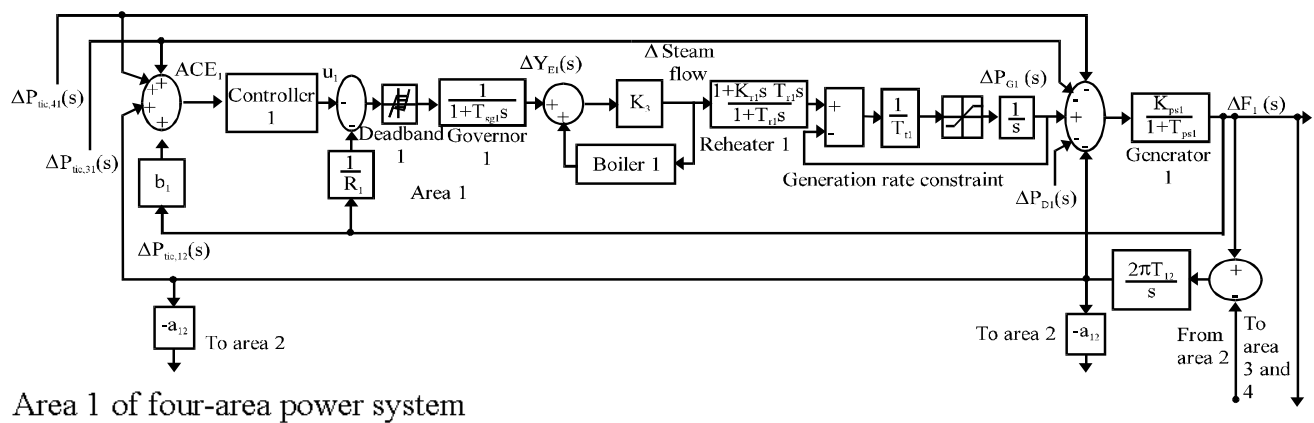

Fig. 3: Area 1 of four-area power system

Where:

$\mathrm{x}=\left[\mathrm{x}_{1}, \mathrm{x}_{2}, \ldots, \mathrm{x}_{22}\right]^{\mathrm{T}} \quad=$ State vector

$\mathrm{u}=\left[\mathrm{u}_{1} \mathrm{u}_{2} \mathrm{u}_{3} \mathrm{u}_{4}\right]^{\mathrm{T}} \quad=$ Control vector

$\Delta \mathrm{P}_{\mathrm{d}}=\mathrm{W}=\left[\mathrm{W}_{1} \mathrm{~W}_{2} \mathrm{~W}_{3} \mathrm{~W}_{4}\right]^{\mathrm{T}}=$ Disturbance vector

$\mathrm{A}$ is system matrix, $\mathrm{B}$ and $\mathrm{F}$ are the input and disturbance distribution matrices, respectively. Let:

$$
\begin{aligned}
& \mathrm{x}_{1}=\Delta \mathrm{f}_{1} \quad \mathrm{x}_{2}=\Delta \mathrm{P}_{\mathrm{g} 1} \quad \mathrm{x}_{3}=\Delta \mathrm{Y}_{\mathrm{E} 1} \quad \mathrm{x}_{4}=\Delta \mathrm{f}_{2} \quad \mathrm{x}_{5}=\Delta \mathrm{P}_{\mathrm{g} 2} \quad \mathrm{x}_{6}=\Delta \mathrm{Y}_{\mathrm{E} 2} \quad \mathrm{x}_{7}=\Delta \mathrm{f}_{3} \\
& \mathrm{x}_{8}=\Delta \mathrm{P}_{\mathrm{g} 3} \quad \mathrm{x}_{9}=\Delta \mathrm{Y}_{\mathrm{E} 3} \quad \mathrm{x}_{10}=\Delta \mathrm{f}_{4} \quad \mathrm{x}_{11}=\Delta \mathrm{P}_{\mathrm{g} 4} \quad \mathrm{x}_{12}=\Delta \mathrm{Y}_{\mathrm{E} 4} \quad \mathrm{x}_{13}=\Delta \mathrm{P}_{\text {tie, }, 12} \quad \mathrm{x}_{14}=\Delta \mathrm{P}_{\text {tie }, 31} \\
& \mathrm{x}_{15}=\Delta \mathrm{P}_{\text {tie, } 41} \quad \mathrm{x}_{16}=\Delta \mathrm{P}_{\text {tie }, 34} \quad \mathrm{x}_{17}=\Delta \mathrm{P}_{\text {tie, } 32} \quad \mathrm{x}_{18}=\Delta \mathrm{P}_{\text {tie }, 42} \quad \mathrm{x}_{19}=\int \mathrm{ACE}_{1} \mathrm{dt} \quad \mathrm{x}_{20}=\int A C \mathrm{ACE}_{2} \mathrm{dt} \\
& \mathrm{x}_{21}=\int \mathrm{ACE}_{3} \mathrm{dt} \quad \mathrm{x}_{22}=\int \mathrm{ACE}_{4} \mathrm{dt} \quad \mathrm{w}_{1}=\Delta \mathrm{P}_{\mathrm{d} 1} \quad \mathrm{w}_{2}=\Delta \mathrm{P}_{\mathrm{d} 2} \quad \mathrm{w}_{3}=\Delta \mathrm{P}_{\mathrm{d} 3} \quad \mathrm{~W}_{4}=\Delta \mathrm{P}_{\mathrm{d} 4}
\end{aligned}
$$

So, the matrices $\mathrm{B}$ and $\mathrm{F}$ are given as: 


$$
\begin{aligned}
& \mathrm{B}^{\mathrm{T}}=\left[\begin{array}{cccccccccccccccccccccc}
0 & 0 & \frac{1}{\mathrm{~T}_{\mathrm{sg} 1}} & 0 & 0 & 0 & 0 & 0 & 0 & 0 & 0 & 0 & 0 & 0 & 0 & 0 & 0 & 0 & 0 & 0 & 0 & 0 \\
0 & 0 & 0 & 0 & 0 & \frac{1}{\mathrm{~T}_{\mathrm{sg} 2}} & 0 & 0 & 0 & 0 & 0 & 0 & 0 & 0 & 0 & 0 & 0 & 0 & 0 & 0 & 0 & 0 \\
0 & 0 & 0 & 0 & 0 & 0 & 0 & 0 & \frac{1}{\mathrm{~T}_{\mathrm{sg} 3}} & 0 & 0 & 0 & 0 & 0 & 0 & 0 & 0 & 0 & 0 & 0 & 0 & 0 \\
0 & 0 & 0 & 0 & 0 & 0 & 0 & 0 & 0 & 0 & 0 & \frac{1}{\mathrm{~T}_{\mathrm{sg} 4}} & 0 & 0 & 0 & 0 & 0 & 0 & 0 & 0 & 0 & 0
\end{array}\right] \\
& \mathrm{F}^{\mathrm{T}}=\left[\begin{array}{cccccccccccccccccccccc}
-\frac{\mathrm{K}_{\mathrm{ps} 1}}{\mathrm{~T}_{\mathrm{ps} 1}} & 0 & 0 & 0 & 0 & 0 & 0 & 0 & 0 & 0 & 0 & 0 & 0 & 0 & 0 & 0 & 0 & 0 & 0 & 0 & 0 & 0 \\
0 & 0 & 0 & -\frac{\mathrm{K}_{\mathrm{ps} 2}}{\mathrm{~T}_{\mathrm{p} 22}} & 0 & 0 & 0 & 0 & 0 & 0 & 0 & 0 & 0 & 0 & 0 & 0 & 0 & 0 & 0 & 0 & 0 & 0 \\
0 & 0 & 0 & 0 & 0 & 0 & -\frac{\mathrm{K}_{\mathrm{ps} 3}}{\mathrm{~T}_{\mathrm{ps} 3}} & 0 & 0 & 0 & 0 & 0 & 0 & 0 & 0 & 0 & 0 & 0 & 0 & 0 & 0 & 0 \\
0 & 0 & 0 & 0 & 0 & 0 & 0 & 0 & 0 & -\frac{\mathrm{K}_{\mathrm{p} s 4}}{\mathrm{~T}_{\mathrm{ps} 4}} & 0 & 0 & 0 & 0 & 0 & 0 & 0 & 0 & 0 & 0 & 0 & 0
\end{array}\right]
\end{aligned}
$$

The control signals $\mathrm{u}_{1}-\mathrm{u}_{4}$ for the speed changers of the four-area power system will be given as:

where:

$$
\begin{aligned}
& \mathrm{u}_{1}=-\mathrm{k}_{\mathrm{i} 1} \mathrm{x}_{19}=-\mathrm{k}_{\mathrm{i} 1} \int A C E_{1} \mathrm{dt}=\Delta \mathrm{P}_{\mathrm{C} 1}(\mathrm{~s}) \\
& \mathrm{u}_{2}=-\mathrm{k}_{\mathrm{i} 2} \mathrm{x}_{20}=-\mathrm{k}_{\mathrm{i} 2} \int \mathrm{ACE}_{2} \mathrm{dt}=\Delta \mathrm{P}_{\mathrm{C} 2}(\mathrm{~s}) \\
& \mathrm{u}_{3}=-\mathrm{k}_{\mathrm{i} 3} \mathrm{x}_{21}=-\mathrm{k}_{\mathrm{i} 3} \int \mathrm{ACE}_{3} \mathrm{dt}=\Delta \mathrm{P}_{\mathrm{C} 3}(\mathrm{~s}) \\
& \mathrm{u}_{4}=-\mathrm{k}_{\mathrm{i} 4} \mathrm{x}_{22}=-\mathrm{k}_{\mathrm{i} 4} \int \mathrm{ACE}_{4} \mathrm{dt}=\Delta \mathrm{P}_{\mathrm{C4}}(\mathrm{s}) \\
& \mathrm{x}_{19}=\int \mathrm{ACE}_{1} \mathrm{dt}, \quad \mathrm{x}_{20}=\int \mathrm{ACE}_{2} \mathrm{dt} \\
& \mathrm{x}_{21}=\int \mathrm{ACE}_{3} \mathrm{dt}, \quad \mathrm{x}_{22}=\int \mathrm{ACE}_{4} \mathrm{dt}
\end{aligned}
$$

$$
\begin{gathered}
\mathrm{ACE}_{1}=\Delta \mathrm{P}_{\text {tie, } 12}+\Delta \mathrm{P}_{\text {tie, } 13}+\Delta \mathrm{P}_{\text {tie, } 14}+\mathrm{b}_{1} \Delta \mathrm{f}_{1} \\
\mathrm{ACE}_{2}=\Delta \mathrm{P}_{\text {tie, }, 21}+\Delta \mathrm{P}_{\text {tie, } 23}+\Delta \mathrm{P}_{\text {tie, } 24}+\mathrm{b}_{2} \Delta \mathrm{f}_{2} \\
\mathrm{ACE}_{3}=\Delta \mathrm{P}_{\text {tie, } 31}+\Delta \mathrm{P}_{\text {tie, } 32}+\Delta \mathrm{P}_{\text {tie, } 34}+\mathrm{b}_{3} \Delta \mathrm{f}_{3} \\
\mathrm{ACE}_{4}=\Delta \mathrm{P}_{\text {tie, } 41}+\Delta \mathrm{P}_{\text {tie, } 42}+\Delta \mathrm{P}_{\text {tie, } 43}+\mathrm{b}_{4} \Delta \mathrm{f}_{4}
\end{gathered}
$$

Where:

$\mathrm{K}_{\mathrm{ii}} \quad=$ Integral gain

$\mathrm{ACE}_{\mathrm{i}}=$ The area control error

$\Delta \mathrm{p}_{\mathrm{c}}=$ The change in speed changer setting of the ith area

Using Eq. 2 and 3, B merges in A and Eq. 1 turns to:

where, $\mathrm{A}$ is given as:

$$
\dot{\mathrm{x}}=\mathrm{Ax}+\mathrm{FW}
$$




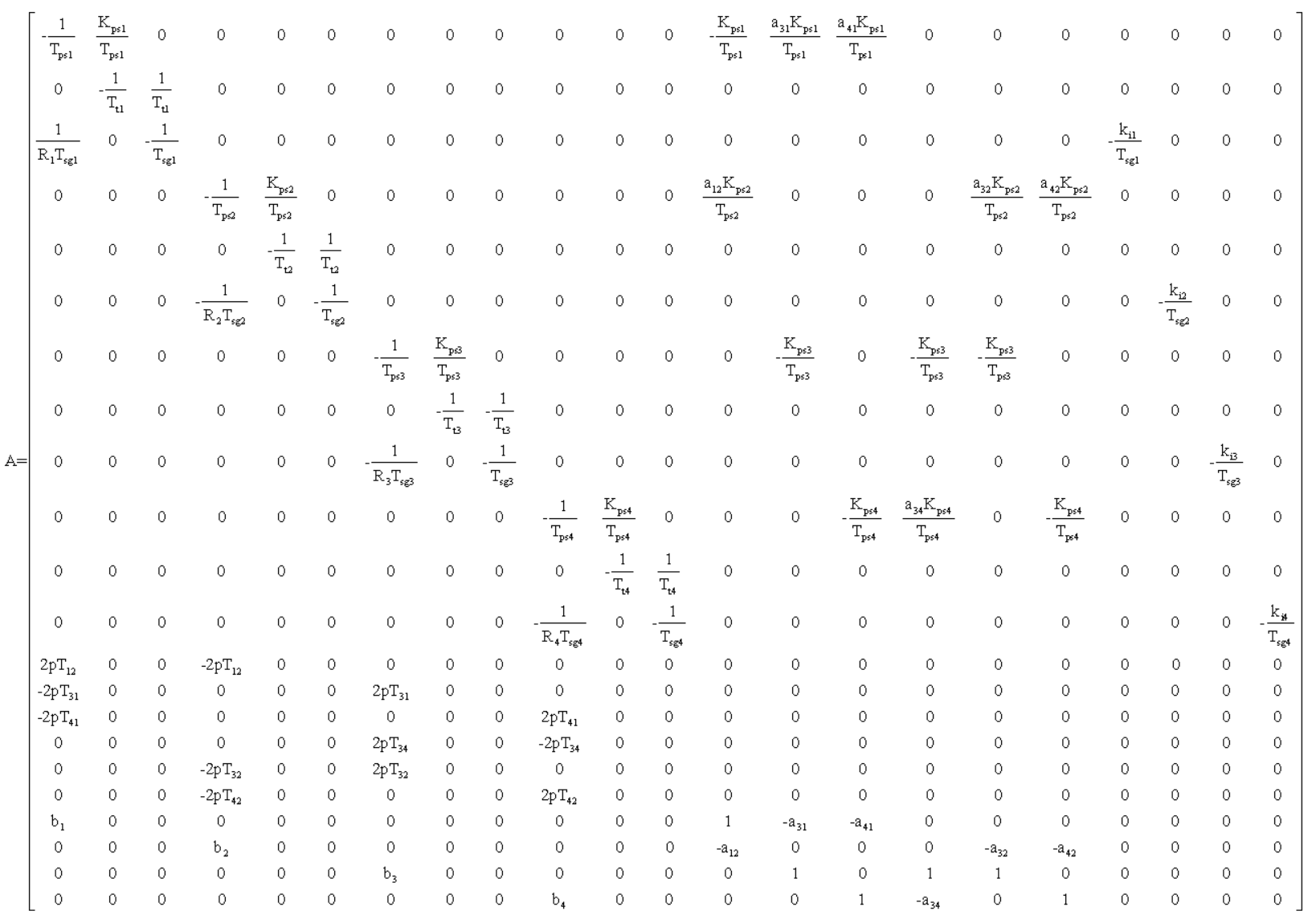

Considering $\Delta \mathrm{f}_{1}-\Delta \mathrm{f}_{4}$ (i.e., change in frequency) and $\Delta \mathrm{P}_{\text {tie, } 12}$ (change in tie line power) as system output variables then output matrix will be the form of:

where, $\mathrm{D}=0$ and $\mathrm{C}$ and $\mathrm{X}$ are given as:

$$
\mathrm{y}=\mathrm{Cx}+\mathrm{Dw}
$$

$$
\mathrm{C}=\left[\begin{array}{llllllllllllllllllllll}
1 & 0 & 0 & 0 & 0 & 0 & 0 & 0 & 0 & 0 & 0 & 0 & 0 & 0 & 0 & 0 & 0 & 0 & 0 & 0 & 0 & 0 \\
0 & 0 & 0 & 1 & 0 & 0 & 0 & 0 & 0 & 0 & 0 & 0 & 0 & 0 & 0 & 0 & 0 & 0 & 0 & 0 & 0 & 0 \\
0 & 0 & 0 & 0 & 0 & 0 & 1 & 0 & 0 & 0 & 0 & 0 & 0 & 0 & 0 & 0 & 0 & 0 & 0 & 0 & 0 & 0 \\
0 & 0 & 0 & 0 & 0 & 0 & 0 & 0 & 0 & 1 & 0 & 0 & 0 & 0 & 0 & 0 & 0 & 0 & 0 & 0 & 0 & 0 \\
0 & 0 & 0 & 0 & 0 & 0 & 0 & 0 & 0 & 0 & 0 & 0 & 1 & 0 & 0 & 0 & 0 & 0 & 0 & 0 & 0 & 0
\end{array}\right]
$$

$\mathrm{x}^{\mathrm{T}}=\left[\mathrm{x}_{1}, \mathrm{x}_{2}, \mathrm{x}_{3}, \ldots, \mathrm{x}_{21}, \mathrm{x}_{22}\right]$

The control signal for the PI controller can be given in the following equation as:

$$
u_{i}=-K_{p i} A C E_{i}-\int K_{i i} A C E_{i} d t
$$

Where, $\mathrm{K}_{\mathrm{pi}}$ and $\mathrm{K}_{\mathrm{ii}}$ are respectively, the proportional and integral gains of the PI controller. The detailed block diagram modeling of four-area thermal power system, investigated in this study is shown in Fig. 3 for area 1.
All areas 1-4 comprise reheat thermal system with governor deadband, generation rate constraint nonlinearities and boiler dynamics. The list of symbols of the system is given in Appendix A and all the data used is shown in Appendix B.

Governor dead band: The detailed transfer function models of the speed governors and turbines are discussed in (Tripathy et al. 1992). Governor Dead Band (GDB) is defined as the total magnitude of a sustained speed change within which there is no resulting change in valve position. The Backlash non-linearity tends to 
produce continuous sinusoidal oscillations with a time period of about $2 \mathrm{sec}$ (Tripathy et al., 1992). The speed governor dead band has significant effect on the dynamic performance of load frequency control system. Describing function approach is used to incorporate the governor dead band non-linearity (Tripathy et al., 1984). The hysteresis type of non-linearities is expressed as:

$$
y=F(x, \dot{x}) \text { rather than } y=F(x)
$$

To solve the non-linear problem, it is necessary to make the basic assumption that the variable $\mathrm{x}$ appearing in Eq. 6 is sufficiently close to a sinusoidal Eq. 7 that is:

$$
\mathrm{x} \approx \mathrm{A} \sin \mathrm{w}_{0} \mathrm{t}
$$

Where, $\mathrm{A}$ is amplitude of oscillation and $\mathrm{w}_{0}$ is frequency of oscillation:

$$
\mathrm{W}_{0}=2 \pi \mathrm{f}_{0}=\pi
$$

As the variable function is complex and periodic function of time, it can be developed in a Fourier series as (Tripathy et al., 1984):

$$
F(x, \dot{x})=F^{0}+N_{1} x+\frac{N_{2}}{w_{0}} \dot{x}
$$

To solve this, it is a reasonable good to consider the first three terms only. The corresponding coefficients are:

$$
\begin{aligned}
& F^{0}=\frac{1}{2 \pi} \int_{0}^{2 \pi} F\left(A \sin w_{0} t, A w_{0} \cos w_{0} t\right) d\left(w_{0} t\right) \\
& N_{1}=\frac{1}{\pi A} \int_{0}^{2 \pi} F\left(A \sin w_{0} t, A w_{0} \cos w_{0} t\right) \sin w_{0} t d\left(w_{0} t\right) \\
& N_{2}=\frac{1}{\pi A} \int_{0}^{2 \pi} F\left(A \sin w_{0} t, A w_{0} \cos w_{0} t\right) \cos w_{0} t d\left(w_{0} t\right)
\end{aligned}
$$

As the Backlash non-linearity is symmetrical about the origin, $\mathrm{F}^{0}$ is zero. For the analysis in this study, Backlash is chosen $0.05 \%$, approximately (Tripathy et al., 1992). The fourier coefficients are derived as:

$$
\mathrm{N}_{1}=0.8 \text { and } \mathrm{N}_{2}=-0.2
$$

Thus, Eq. 8 can be written as follows:

$$
\mathrm{F}(\mathrm{x}, \dot{\mathrm{x}})=0.8 \mathrm{x}-\frac{0.2}{\pi} \dot{\mathrm{x}}
$$

Thus, transfer function of the governor taking deadband into account can be express as:

$$
G_{s g i}(s)=\frac{N_{1}+N_{2} s}{1+T_{s g i} s}
$$

or:

$$
\mathrm{G}_{\mathrm{sgi}}(\mathrm{s})=\frac{0.8-\frac{0.2}{\pi} \mathrm{s}}{1+\mathrm{T}_{\mathrm{sg}} \mathrm{s}}
$$

Generation rate constraint: In practical steam turbine systems due to themodynamic and mechanical constraints, there is a limit to the rate at which its output power $\left(\Delta \dot{\mathrm{P}}_{\mathrm{g}}\right)$ can be changed. This limit is referred as Generation Rate Constraint (GRC). It is obvious that the dynamic responses of the system with the presence of GRC have larger overshoots and longer settling times compared to the system without GRC (Panda et al., 2009). For all the four thermal control areas, a generating rate limitation of 0.1 p.u. $\mathrm{MW} / \mathrm{min}$ is considered (Pothiya et al., 2007; Kocaarslan et al., 1999), i.e.:

$$
\Delta \dot{\mathrm{P}}_{\mathrm{g}} \leq 0.1 \text { p.u. MW } / \text { Min. }=0.0017 \text { p.u. } \mathrm{MW} / \mathrm{sec}=\delta
$$

The GRC is taken into account by adding a limiter $(\delta= \pm 0.0017)$ to the turbine power.

Boiler dynamics: The changes in generation are initiated by turbine control valves. Changes in steam flow and pressure are sensed and thus, control the combustion rate. Boiler is a device meant for producing steam under pressure. The model shown in Fig. 4 is basically for a drum type boiler (Pothiya et al., 2007). This includes the long term dynamics of fuel and steam flow on boiler drum pressure. Representations for combustion controls are also incorporated. Even though, the model is basically for

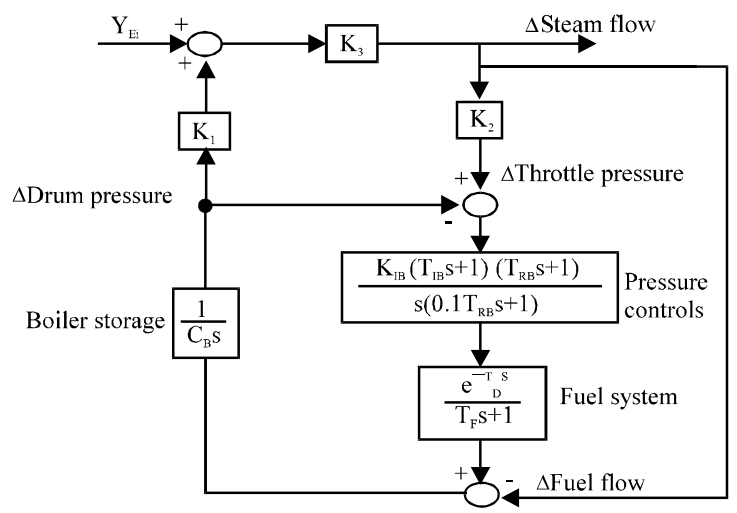

Fig. 4: Block diagram of boiler dynamics 
a drum type boiler, similar responses have been observed for once-through boilers and pressurized water reactors (Mills and B'Rells, 1973). An oil fired boiler system has been employed in this study such boilers respond to load demand changes more quickly than coal-fired units (Tripathy et al., 1992, 1984). The boiler receives feed water which has been preheated in the economizer and provides saturated steam outflow. Recirculation boiler makes use of a drum to separate steam flow from the recirculation water so that it can proceed to the super heater as a heatable vapour. The changes in generations are initiated by turbine control valves and the boiler controls respond with necessary control action change in steam flow and change in throttle pressure, the combustion rate and hence the boiler output. The model can be used to study the responses of coal fired units with poorly tuned (oscillatory) combustion controls, coal fired units with well tuned controls and well tuned oil or gas fired units.

Fuzzy logic PI type controller: Fuzzy logic control is based on a logical system called fuzzy logic which is much closer in spirit to human thinking and natural language than classical logical systems. Now-a-days, fuzzy logic is used in almost all sectors of industry and science.

The main goal of LFC in interconnected power systems is to maintain the balance between production and consumption. Because of the complexity and multi-variable conditions of the power system, conventional control methods may not give satisfactory solutions. On the other hand, their robustness and reliability make fuzzy controllers useful in solving a wide range of control problems. Artificial intelligence based gain scheduling is an alternative technique commonly used in designing controllers for non-linear systems.

Fuzzy system transforms a human knowledge into mathematical formula. Therefore, fuzzy set theory based approach, in recent years, has emerged as a complement tool to mathematical approaches for solving power system problems. Fuzzy set theory and fuzzy logic establish the rules of a non-linear mapping. These rules are obtained based on experiments of the process step response, error signal and its time derivative (Kocaarslan et al., 1999). The FLPI controller (Fig. 5) to solve the four-area LFC problem of Fig. 2 consists of a fuzzy logic controller and a conventional PI controller connected in series. The fuzzy

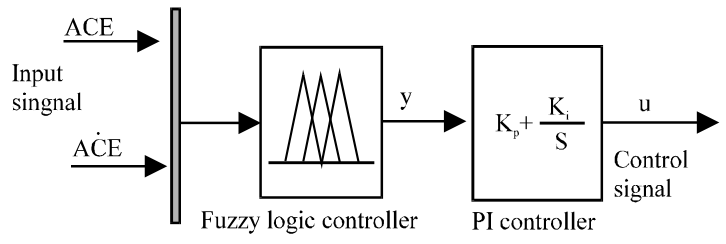

Fig. 5: Structure of fuzzy logic based proportional integral controller logic controller has two input signals, namely $\mathrm{ACE}$ $\mathrm{ACE}$ and then the output signal (y) of the fuzzy logic controller is the input signal of the conventional PI controller. Finally, the output signal from the conventional PI controller called the control signal $(u)$ is used for controlling the LFC in the interconnected power system. The fuzzy logic controller is comprised of four main components; the fuzzification, the inference engine, the rule base and the defuzzification as shown in Fig. 6. The fuzzifier transforms the numeric/crisp value into fuzzy sets so that this operation is called fuzzification. The main component of the fuzzy logic controller is the inference engine which performs all logic manipulations in a fuzzy logic controller. The rule base consists of membership functions and control rules. Last, the results of the inference process is an output represented by a fuzzy set, however the output of the fuzzy logic controller should be a numeric/crisp value. Therefore, fuzzy set is transformed into a numeric value by using the defuzzifier so that this operation is called defuzzification. The control signal is given by:

$$
\mathrm{u}_{\mathrm{i}}(\mathrm{t})=-\left(\mathrm{K}_{\mathrm{pi}} \mathrm{y}+\int \mathrm{K}_{\mathrm{ii}} \mathrm{ydt}\right)
$$

$\mathrm{K}_{\mathrm{pi}}$ and $\mathrm{K}_{\mathrm{ii}}$ are the proportional and the integral gains, respectively. For the proposed study, Mamdani fuzzy inference engine was selected and The Centroid Method is used in defuzzification process. In this research, the appropriate rules are shown in Table 1. Fuzzy logic shows experience and preference through membership functions. These functions have different shapes depending on system experts' experience (Cam and Kocaarslan, 2005). The membership functions of the fuzzy logic controller for inputs and output consist of three memberships functions (two-inputs and one-output) (Fig. 7). Each membership function has seven memberships, comprising two trapezoidal and five triangular memberships. The number of rules in inference mechanism is taken seven. Therefore, 49 control rules are used for this study. The ranges of the membership functions are chosen from simulation results. All memberships are selected to describe all linguistic variables. These functions have different shapes depending on system experts' experience.For the determination of the control rules, it can be more complicated than membership functions which depend on

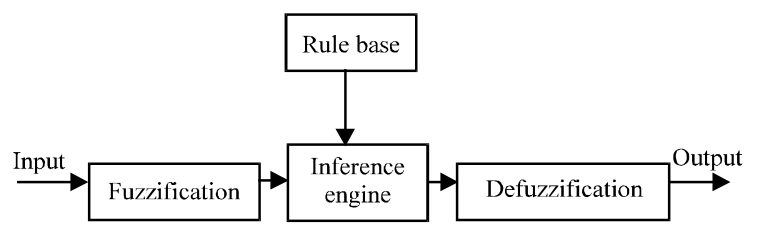

Fig. 6: Components of a fuzzy controller 

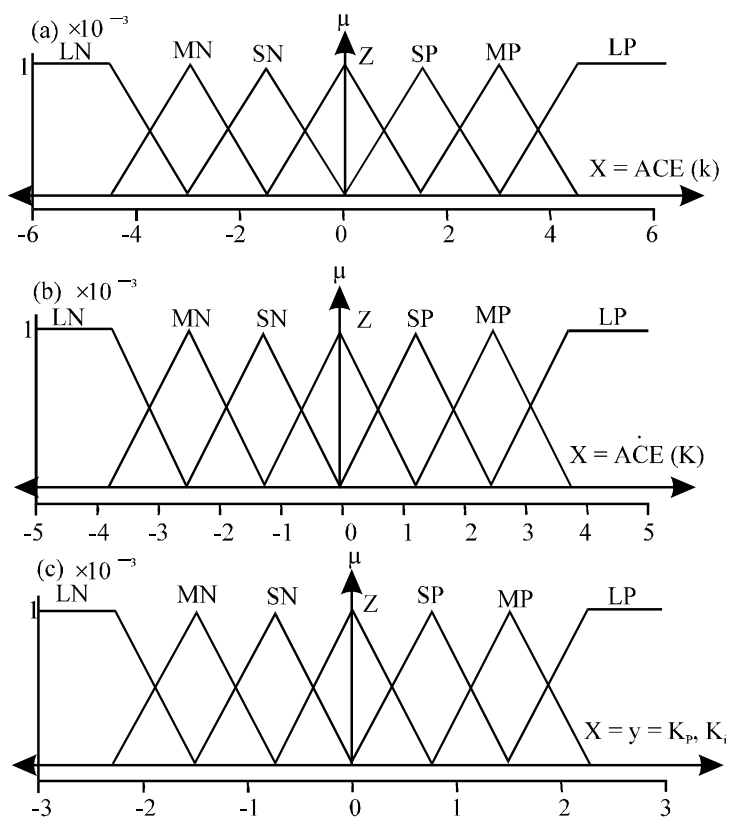

Fig. 7: Membership functions of a) ACE; b) A\&E and c) $\mathrm{y}$

Table 1: Control rules for FLPI controller

\begin{tabular}{|c|c|c|c|c|c|c|c|}
\hline \multirow[b]{2}{*}{$\triangle \mathrm{ACE}$} & \multicolumn{7}{|c|}{$A \& E$} \\
\hline & $\mathrm{LN}$ & $\mathrm{MN}$ & SN & $\mathrm{Z}$ & SP & MP & LP \\
\hline $\mathrm{LN}$ & $\mathrm{LP}$ & LP & $\mathrm{LP}$ & MP & MP & SP & Z \\
\hline $\mathrm{MN}$ & LP & MP & MP & MP & SP & $\mathrm{Z}$ & $\mathrm{SN}$ \\
\hline SN & LP & MP & SP & SP & $\mathrm{Z}$ & SN & $\mathrm{MN}$ \\
\hline Z & MP & MP & SP & Z & SN & $\mathrm{MN}$ & $\mathrm{MN}$ \\
\hline SP & MP & SP & Z & SN & SN & $\mathrm{MN}$ & LN \\
\hline MP & SP & $\mathrm{Z}$ & $\mathrm{SN}$ & $\mathrm{MN}$ & $\mathrm{MN}$ & $\mathrm{MN}$ & $\mathrm{LN}$ \\
\hline LP & $\mathrm{Z}$ & SN & $\mathrm{MN}$ & $\mathrm{MN}$ & $\mathrm{LN}$ & $\mathrm{LN}$ & $\mathrm{LN}$ \\
\hline
\end{tabular}

LN: Large Negative; MN: Medium Negative; SN: Small Negative; Z: Zero; SP: Small Positive; MP: Medium Positive; LP: Large Positive

the designer experiences and actual physical system. The control rules build from the if-then statement (if input 1 and 2 then output 1 ). Table 1 shows the appropriate rule bases in this study. For example, the 3rd row and column in Table 1 indicates if ACE is SN and ACE is SN then $\mathrm{y}$ is SP.

\section{RESULTS AND DISCUSSION}

Simulations were performed using the conventional proportional Plus Integral (PI) controller and the proposed FLPI controllers applied to a four-area interconnected electrical power system with 0.01 p.u. MW step load disturbance in area 1 . The same system data given in Appendix B is used in both the controllers for a comparison. The implementation worked with Matlab 7.5 Simulink software. The simulations were run on a personal computer Intel Core2Duo CPU T5450@1.66 GHz, $982 \mathrm{MHz}, 2 \mathrm{~GB}$ of RAM under Window XP. The frequency
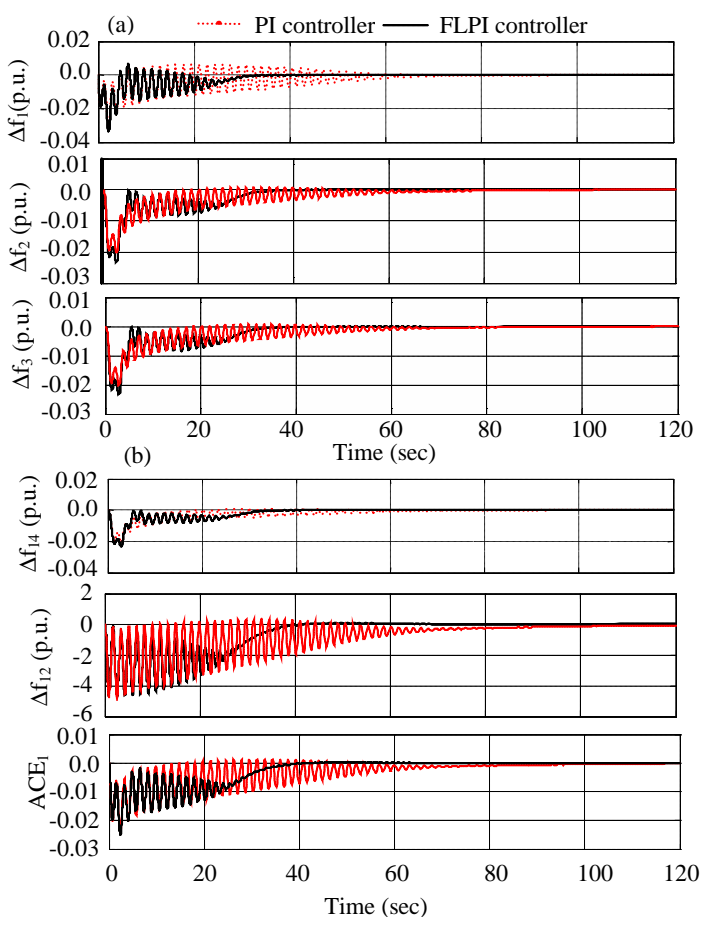

Fig. 8: Deviation in frequency of a) area $1-3$; b) area 4 change in tie line power $\left(\Delta \mathrm{P}_{\mathrm{tie}, 12}\right)$ and Area Control Error in area $1\left(\mathrm{ACE}_{1}\right)$ for $1 \%$ load change in area $1\left(\Delta \mathrm{p}_{\mathrm{d} 1}=0.01\right.$ p.u. $)$

Table 2: Step load change and maximum overshoots

\begin{tabular}{lcc}
$\begin{array}{l}\text { Deviation in } \\
\text { frequency }\left(\Delta \mathrm{f}_{1}\right)\end{array}$ & $\begin{array}{c}\text { Settling time (sec) for 5\% } \\
\text { band of step change }\end{array}$ & $\begin{array}{c}\text { Peak overshoot } \\
\text { (p.u.) }\end{array}$ \\
\hline $\begin{array}{l}\text { FLPI controller }\left(\mathrm{T}_{\mathrm{a}}\right) \\
\begin{array}{l}\text { B. Anand's study for two-area } \\
\text { system }\end{array}\end{array}$ & 33.8030 & -0.0335 \\
PI controller $\left(\mathrm{T}_{\mathrm{b}}\right)$ & 42.5000 & -0.0484 \\
\hline
\end{tabular}

deviations of the all four-areas after a sudden load change in area 1 are shown in Fig. 8 and 9. The proposed fuzzy logic controller is significantly superior to the conventional PI controller. It gives a better performance than the PI controller. The settling time and peak overshoots are reduced considerably as shown in Fig. 8 and 9. The simulation results of frequency deviations and tie line power deviation with FLPI controller advocates, the proposed controller's suitability for LFC schemes which is also verified through proper settlement of area control error. The area control error is defined as a quantity reflecting the deficiency or excess of power within a control area. Here, the ACE of all four areas is also effectively controlled with proposed FLPI controller. The frequency deviation of area 1 with settling time for $5 \%$ band of the step load change and maximum overshoots are shown in Table 2. The comparison of 


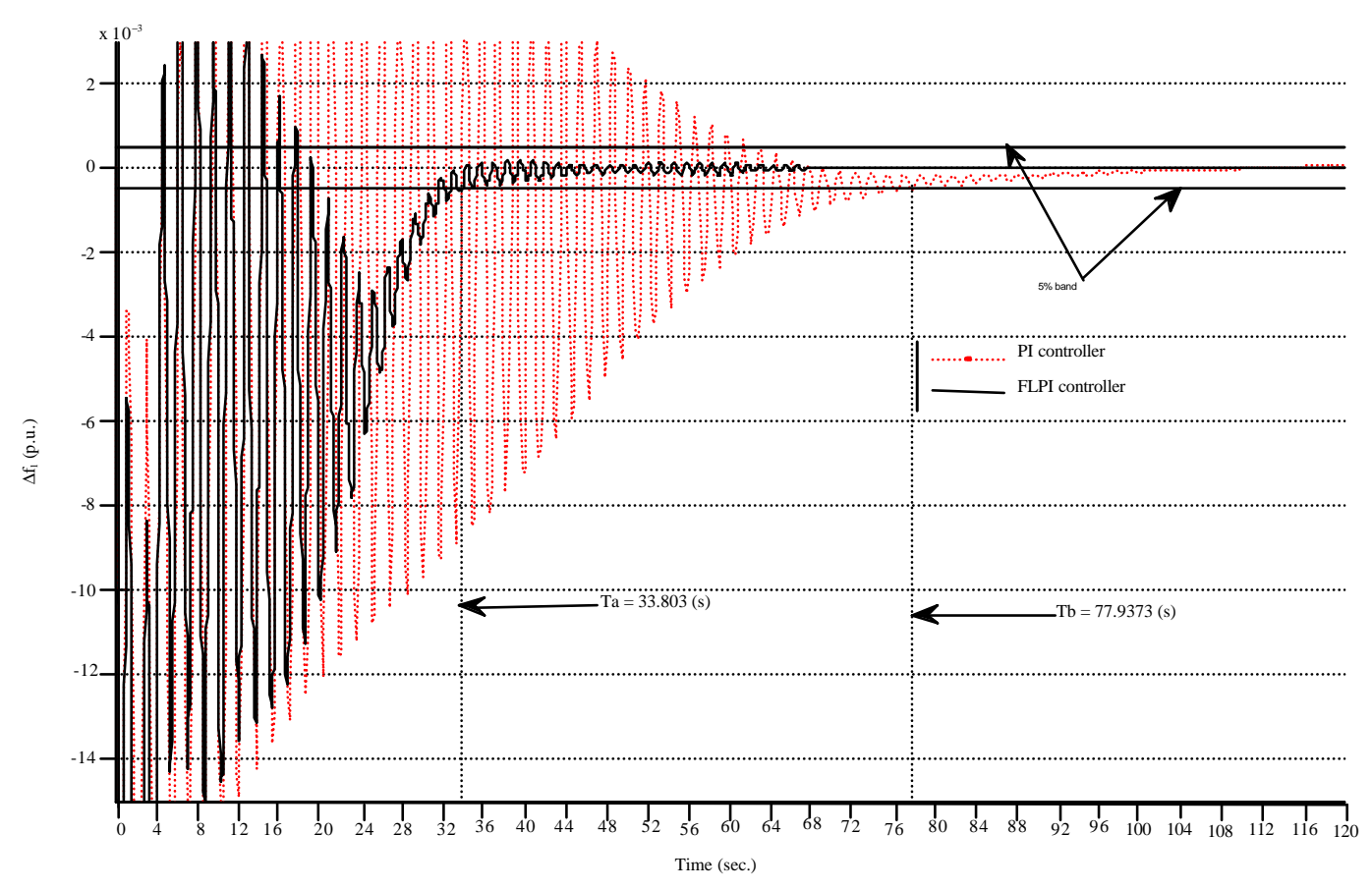

Fig. 9: Deviation of frequency of area 1 in a large scale and settling times for proposed FLPI controller $\left(\mathrm{T}_{\mathrm{a}}\right)$ and conventional PI controller $\left(\mathrm{T}_{\mathrm{b}}\right)$ for $1 \%$ load change in area $1\left(\Delta \mathrm{P}_{\mathrm{d} 1}=0.01\right.$ p.u. $)$
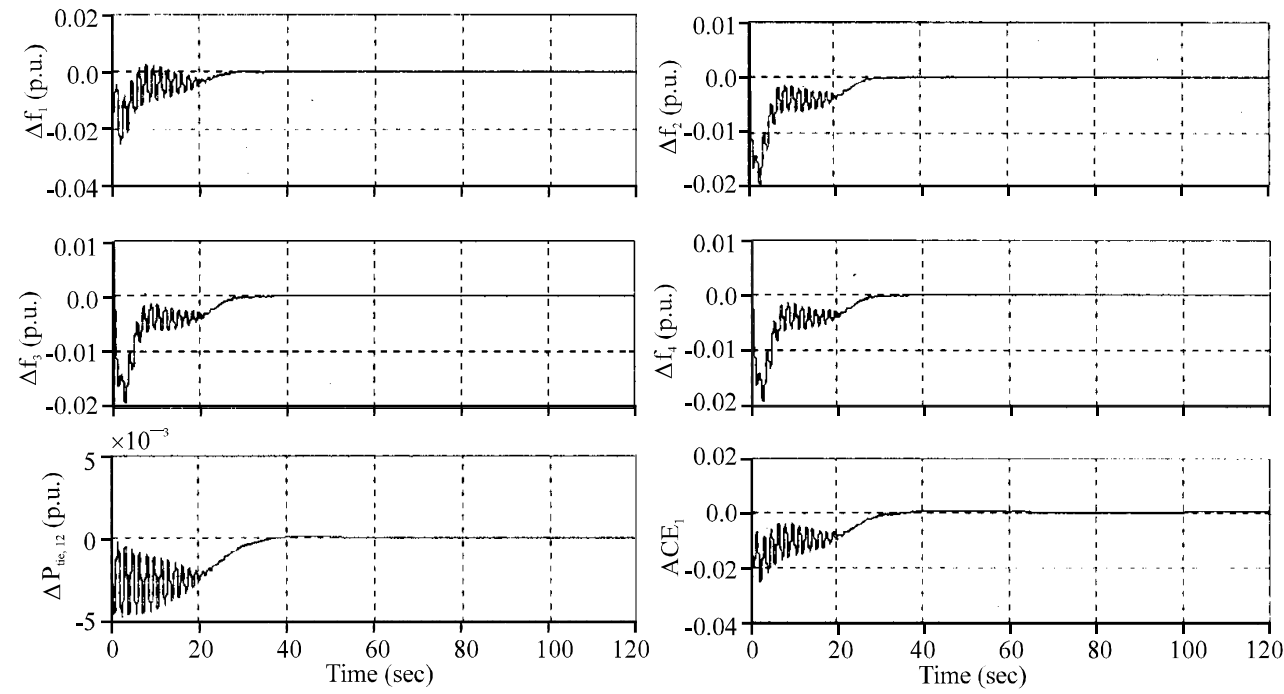

Fig. 10: Deviation in frequency of area 1-4 change in tie line power $\left(\Delta \mathrm{P}_{\text {tiel2 }}\right)$ and Area Control Error in area $1\left(\mathrm{ACE}_{1}\right)$ for $1 \%$ p.u. load change in area 1 with FLPI controller at $+35 \%$ change in parameters $\left(\Delta \mathrm{P}_{\mathrm{d} 1}=0.01\right.$ p.u. $)$

dynamic performances of the proposed FLPI controller with the other controller shows better results of FLPI in terms of lesser settling time and peak overshoot. The simulation results show that proposed controller for load frequency control is giving approximately $20.47 \%$ reduction in settling time and $37.79 \%$ reduction in peak overshoots when compared with B. Anand's study (for two-area with same values of parameters). In the analysis of the simulation results, the frequency deviation results were also used to calculate the Integral Absolute Error (IAE) and Integral of Time multiplied Absolute Error (ITAE) of area 1 for both the controllers as given in Eq. 12 for $120 \mathrm{sec}$ of simulation time:

$$
\mathrm{IAE}=\int_{0}^{120}\left|\Delta \mathrm{f}_{1}\right| \mathrm{dt}, \mathrm{ITAE}=\int_{0}^{120} \mathrm{t}\left|\Delta \mathrm{f}_{1}\right| \mathrm{dt}
$$



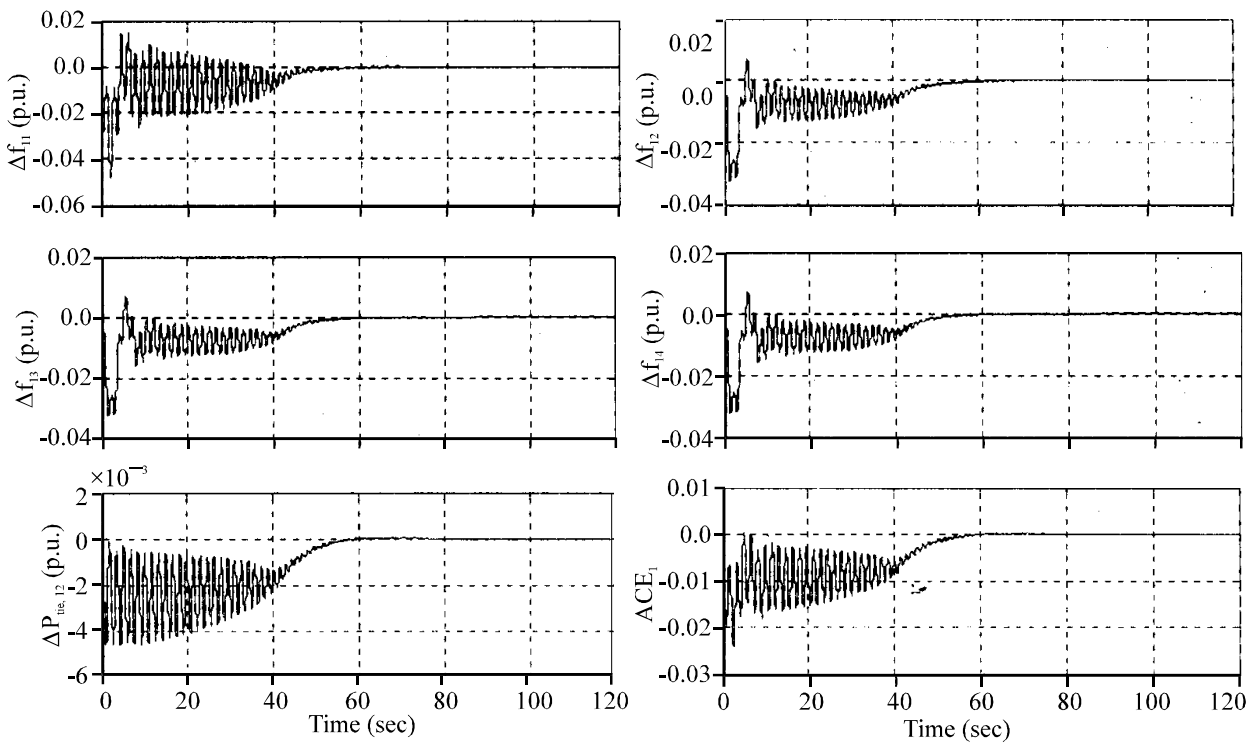

Fig. 11: Deviation in frequency of area 1-4 change in tie line power $\left(\Delta \mathrm{P}_{\text {tie, 12 }}\right)$ and Area Control Error in area $1\left(\mathrm{ACE}_{1}\right)$ for $1 \%$ load change in area 1 with FLPI controller at $-35 \%$ change in parameters $\left(\Delta \mathrm{P}_{\mathrm{d} 1}=0.01\right.$ p.u. $)$

Table 3: System performance of controllers

\begin{tabular}{lcr}
\hline Controllers & IAE & ITAE \\
FLPI & 0.2163 & 2.530 \\
PI controller & 0.3438 & 7.953 \\
\hline
\end{tabular}

The values of IAE and ITAE are calculated under the occurrence of the load disturbance in area 1 . Table 3 shows the values of the IAE and ITAE of $\Delta \mathrm{f}_{1}$ for both controllers. System performance of the controllers in terms of Integral Absolute Error (IAE) and Integral of Time multiplied Absolute Error (ITAE) for frequency deviation of area $1\left(\Delta \mathrm{f}_{1}\right)$ shown in Table 3 also shows that proposed FLPI has less Absolute Integral Error (IAE) and Integral of Time multiplied Absolute Error (ITAE) as compared to convention PI controller. Other simulations in Fig. 10 and 11 are carried out for $\pm 35 \%$ change in parameter values (mainly $\mathrm{b}_{\mathrm{i}}, \mathrm{T}_{\mathrm{ij}}$ and $\mathrm{T}_{\mathrm{psi}}$ ) of the system. In Fig. 10, the responses are shown with $+35 \%$ change in system parameter values at $1 \%$ load change in area 1 . It indicates that change in frequency (in area 1-4), change in tie line power $\mathrm{P}_{\text {tie, } 12}$ and Area Control Error $\left(\mathrm{ACE}_{1}\right)$ are getting settled down within reasonably good time. Similarly with same amount of disturbance in area 1 , it is observed that the system is settled down quite fast with $-35 \%$ changes in system parameter values (Fig. 11). This justifies the robustness of the proposed controller which is capable to withstand the changes in dynamic parameters of the system.

\section{CONCLUSION}

In this study, a fuzzy logic PI controller is designed for automatic load frequency control in four-area electrical power system. The controller's performance is observed on the basis of four parameters, i.e., settling time, peak overshoot, integral absolute error and integral of time multiplied absolute error. From the results, it is concluded that the proposed controller provide better dynamic performance when compared with conventional PI controller applied to four-area power system considering reheat thermal turbine with generation rate constraint, governor deadband and boiler dynamics. Robustness of the FLPI controller is also checked with changing parameters of the system under study. In addition, the proposed controller is very simple and easy to implement.

\section{APPENDIX}

\begin{tabular}{|c|c|c|}
\hline \multicolumn{3}{|c|}{ A: List of symbols: } \\
\hline$\Delta \mathrm{f}_{\mathrm{i}}$ & $=$ & Incremental frequency deviation of ith area $\mathrm{Hz}$ p.u. \\
\hline$\Delta \mathrm{P}_{\mathrm{di}}$ & $=$ & Incremental load demand change of ith area, p.u. MW \\
\hline $\mathrm{T}_{\mathrm{ggi}}$ & $=$ & Speed governor time constant of ith area, sec \\
\hline $\mathrm{K}_{\mathrm{sgi}}$ & $=$ & Gain of speed govemor of ith area \\
\hline $\mathrm{R}_{\mathrm{i}}$ & $=$ & Govemor speed regulation of ith area, $\mathrm{Hz} / \mathrm{p} . \mathrm{u} . \mathrm{MW}$ \\
\hline $\mathrm{T}_{\mathrm{ti}}$ & $=$ & Turbine time constant of ith area, sec \\
\hline $\mathrm{K}_{\mathrm{pei}}$ & $=$ & Gain of power system of ith area, $\mathrm{Hz} /$ p.u. MW \\
\hline $\mathrm{T}_{\mathrm{pi}}$ & $=$ & Power system time constant of ith area, sec \\
\hline$\Delta \mathrm{P}_{\mathrm{gi}}$ & $=$ & $\begin{array}{l}\text { Incremental generator/turbine power output change of ith area, } \\
\text { p.u. MW }\end{array}$ \\
\hline$\Delta \mathrm{P}_{\mathrm{ci}}$ & $=$ & Incremental speed changer setting change of ith area, p.u. MW \\
\hline$\Delta \mathrm{y}_{\mathrm{Ei}}$ & $=$ & Incremental steam valve setting change of ith area, p.u. MW \\
\hline & & Gain of integral controller of ith area \\
\hline & & Frequency bias of ith area, p.u. MW/Hz \\
\hline $\mathrm{ACE}_{\mathrm{i}}$ & $=$ & Area control error of ith area, p.u. MW \\
\hline $\mathrm{u}_{\mathrm{i}}$ & $=$ & Control input of ith area \\
\hline & $=$ & Disturbance vector of ith area, p.u. MW \\
\hline$\Delta \mathrm{P}_{\mathrm{te}, \mathrm{ij}}$ & & $\begin{array}{l}\text { Incremental tie line power change of ith and jth area, p.u. } \\
\text { MW }\end{array}$ \\
\hline$a_{i j}$ & $=$ & $P_{n i} / P_{i j}$ \\
\hline$P_{n i}$ & & Rated power of ith area \\
\hline$P_{y j}$ & $=$ & Rated power of jth area \\
\hline $\mathrm{T}_{\mathrm{ij}}$ & & $\begin{array}{l}\text { Tie line synchronizing power co-efficient (p.u.) between area } \\
\mathrm{i} \text { and area } \mathrm{j}\end{array}$ \\
\hline $\mathrm{K}_{\mathrm{n}}$ & $=$ & Transfer function gains of reheats of ith area \\
\hline
\end{tabular}




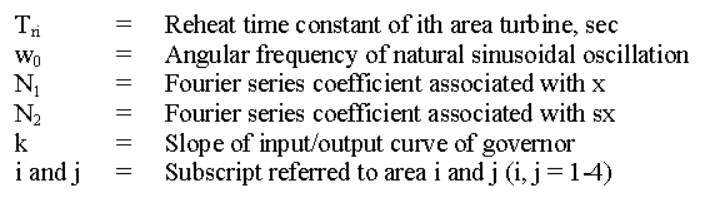

B: Nominal parameters (Cam and Kocaarslan, 2005; Tripathy et $a$., 1992; Pothiya et al., 2007)

(a) System data:

$\mathrm{P}_{\mathrm{ri}}=2000(\mathrm{MW}), \mathrm{P}_{\mathrm{rj}}=2000(\mathrm{MW}), \mathrm{T}_{\mathrm{sgi}}=0.08(\mathrm{sec}), \mathrm{T}_{\mathrm{pei}}=20(\mathrm{sec}), \mathrm{T}_{\mathrm{ti}}$ $=0.03(\mathrm{sec}), \mathrm{R}_{\mathrm{j}}=2.4(\mathrm{~Hz}$ p.u. $/ \mathrm{MW}), \mathrm{T}_{\mathrm{ij}}=0.08674, \mathrm{a}_{\mathrm{ij}}=1, \mathrm{~K}_{\mathrm{pi}}=0.01, \mathrm{~K}_{\mathrm{ii}}$

$=0.04, \mathrm{~K}_{\mathrm{psi}}=120(\mathrm{~Hz}$ p.u. $/ \mathrm{MW}), \mathrm{b}_{\mathrm{i}}=0.425$ (p.u. $\mathrm{MW} / \mathrm{Hz}$ ), $\mathrm{K}_{\mathrm{ri}}=0.5, \mathrm{~T}_{\mathrm{ri}}$

$=10(\mathrm{sec}), \delta= \pm 0.0017$ (p.u. MW/sec), i, j=1-4.

(b) Boiler (oil fired) data:

$\mathrm{K}_{1}=0.85, \mathrm{~K}_{2}=0.095, \mathrm{~K}_{3}=0.92, \mathrm{CB}=200, \mathrm{~T}_{\mathrm{D}}=0, \mathrm{~T}_{\mathrm{F}}=10, \mathrm{~K}_{\mathbb{B}}=0.03$, $\mathrm{T}_{\mathrm{B}}=26, \mathrm{~T}_{\mathrm{RB}}=69$

\section{REFERENCES}

Cam, E. and I. Kocaarslan, 2005. Load frequency control in two area power systems using fuzzy logic controller. Energy Conversion Manage., 46: 233-243.

Chaturvedi, D.K., P.S. Satsangi and P.K. Kalra, 1999. Load frequency control: A generalized neural network approach. Electr. Power Energy Syst., 21: 405-415.

Chidambaram, A. and S. Velusamy, 2005. Decentralized biased controllers for load frequency control of interconnected power systems considering governor dead band non-linearity. IEEE Indicon, 5: 521-525.

Elgerd, O.I., 1982. Electric Energy Systems Theory: An Introduction. McGraw-Hill, New York.

Ertugrul, C. and I. Kocaarslan, 2005. A fuzzy gain scheduling PI controller application for an interconnected electrical-power system. Elect. Power Syst. Res., 73: 267-274.

Fosha, C.E. and O.I. Elgerd, 1970. The megawatt frequency control problem: A new approach via optimal control theory. IEEE Trans. Power Apparatus Syst., 89: 563-577.

Gupta, S.K., 2009. Power System Engineering. 1st Edn., Umesh Publishers, New Delhi.

Jaung, C.F. and C.F. Lu, 2005. Power system load frequency control by genetic fuzzy gain scheduling controller. J. Chinese Inst. Eng., 28: 1013-1018.

Kocaarslan, I., G. Akalýn and T. Erfidan, 1999. Application of fuzzy reasoning to load frequency control in two area power system. Proceedings of the European Control Conference, August 31-September 3, 1999 , Karlsruhe, Germany, pp: 27-31.

Kumar, A., O.P. Malik and G.S. Hope, 1985. Variable structure-system control applied to agc of an interconnected power system. IEEE Proc. Generation Transmission Distribution, 132: 23-29.

Luy, M., I. Kocaarslan, E. Cam and M.C. Taplamacioglu, 2008. Load frequency in single area power system by artificial neural network. Univ. Pitesti Electr. Comput. Sci. Sci. Bull., 8: 26-29.
Malik, O.P., A. Kumar and G.S. Hope, 1988. A load frequency control algorithm based on generalized approach. IEEE Trans. Power Syst., 3: 375-382.

Mathur, H.D. and H.V. Manjunath, 2006. Extended fuzzy logic based integral controller for three area power system with generation rate constraint. Proceedings of the IEEE International Conference on Industrial Technology, December 15-17, 2006, Mumbai, pp: 917-921

Mills, R.J. and W.F. B'Rells, 1973. Automatic generation control part I-Process modeling. IEEE Trans. Power Apparatus Syst., 92: 710-715.

Oysal, Y., 2005. A comparative study of adaptive load frequency controller design in a power system with dynamic neural network models. Energy Conversion Manage., 46: 2656-2668.

Pan, C.T. and C.M. Liaw, 1989. An adaptive controller for power system load-frequency control. IEEE. Trans. Power Syst., 4: 122-128.

Panda, G., S. Panda and C. Ardil, 2009. Automatic generation control of interconnected power system with generation rate constraints by hybrid neuro fuzzy approach. World Acad. Sci. Eng. Technol., 52: 543-548.

Pothiya, S., I. Ngamroo and W. Kongprawechnon, 2007. Design of optimal fuzzy logic-based pid controller using multiple tabu search algorithm for agc including smes units. Proceedings of the 8th International Power Engineering Conference, December 3-6, 2007, Singapore, pp: 838-843

Prasanth, B.V. and S.V.J. Kumar, 2008. Load frequency control for a two area interconnected power system using robust genetic algorithm controller. J. Theor. Applied Inform. Technol., 4: $1204-1212$.

Sadat, H., 2002. Power System Analysis. 2nd Edn., McGraw-Hill, New York, ISBN: 0-07-284869-3.

Sreenath, A., Y.R. Atre and D.R. Patil, 2008. Two area load frequency control with fuzzy gain scheduling of PI controller. Proceedings of the 1st International Conference on Emerging Trends in Engineering and Technology, July 16-18, 2008, Nagpur, Maharashtra, pp: 899-904.

Tripathy, S.C., T.S. Bhatti, C.S. Jha, O.P. Malik and G.S. Hope, 1984. Sampled data automatic generation control analysis with reheat steam turbine and governor deadband effects. IEEE Trans. Power Apparatus Syst., 103: 1045-1050.

Tripathy, S.C., R. Balasubramanian and P.S.C. Nair, 1992. Effect of superconducting magnetic energy storage on automatic generation control considering governor deadband and boiler dynamics. IEEE. Trans. Power Syst., 7: 1266-1273. 